\title{
Persisting Embryonal Infundibular Recess in Morning Glory Syndrome: Clinical Report of a Novel Association
}

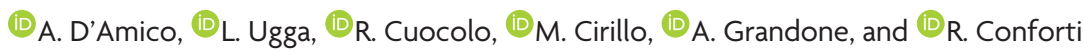

\begin{abstract}
SUMMARY: Morning glory syndrome is characterized by a congenital optic disc defect that resembles the eponymous flower. We present the MR imaging findings of 2 pediatric patients with morning glory disc anomaly and persisting embryonal infundibular recess, another rare malformative finding, a previously unreported association. Neuroradiologists should be aware of the possible presence of a persisting embryonal infundibular recess in patients with morning glory syndrome, to aid in the differential diagnosis including other pituitary malformations such as pituitary stalk duplication.
\end{abstract}

ABBREVIATIONS: MGDA = morning glory disc anomaly; MGS = morning glory syndrome; $\mathrm{PEIR}=$ persisting embryonal infundibular recess

T he morning glory disc anomaly (MGDA) is a rare, congenital ocular defect diagnosed by fundoscopy. It is characterized by a funnel-shaped macropapilla with central neuroglial remnants, surrounded by an elevated, pigmented chorioretinal ring, named after its resemblance to the morning glory flower. ${ }^{1,2}$ While it is usually unilateral, bilateral MGDA may occur. ${ }^{3}$ Even though it may be an isolated finding, it can present in the context of a morning glory syndrome (MGS) when associated with other congenital abnormalities, including craniofacial, skull base, optic pathway, corpus callosum, vascular, and pituitary ones. ${ }^{2,4}$

The embryonal infundibular recess is a funnel-shaped liquoral space of the third ventricle floor extending into the pituitary stalk, normally obliterated during development, whose persistence is defined as persisting embryonal infundibular recess (PEIR). It has been rarely reported ${ }^{5,6}$ and appears as an unusual expansion of the third ventricle floor into the sella turcica with loss of the normal recess contours. At MR imaging, it appears as an intrasellar cyst, communicating with the third ventricle. The sella turcica may be expanded, and the pituitary gland is typically thinned (empty sella).

Received October 22, 2018; accepted after revision January 14, 2019

From the Department of Advanced Biomedical Sciences (A.D., L.U., R. Cuocolo), University of Naples "Federico II," Naples, Italy; and Dipartimento di Scienze Mediche, Chirurgiche, Neurologiche (M.C.), Metaboliche e dell'Invecchiamento, Dipartimento della Donna (A.G.), del Bambino e di Chirurgia Generale e Specialistica, and Dipartimento di Medicina di Precisione (R. Conforti), University of Campania "Luigi Vanvitelli," Naples, Italy.

Please address correspondence to Renato Cuocolo, MD, Department of Advanced Biomedical Sciences, University of Naples “Federico II", Via S. Pansini 5, 80131, Naples, Italy; e-mail: renato.cuocolo@gmail.com; @renatocuocolo

http://dx.doi.org/10.3174/ajnr.A6005
We present 2 patients with fundoscopically confirmed MGDA whose brain MR imaging showed several of the above-mentioned anomalies as well as a PEIR. The association between MGDA and PEIR has not been reported currently, to the best of our knowledge.

\section{Case Series}

Patient 1. This 3-year-old boy presented with short stature and migraine. Fundoscopy revealed a MGDA of the right eye. Several stimulus tests confirmed a complete growth hormone isolated deficiency.

MR imaging showed hypophyseal hypoplasia (Fig 1) and a stubby, thickened, and inferiorly dropped optic chiasm with normal signal intensity (Fig 2). Sagittal images also showed a dysmorphic hypothalamic infundibulum and pituitary stalk. Indeed, there was a direct communication between the third ventricle and the sellar cavity, suggesting a PEIR (Fig 1). The acquisition of a constructive interference in steady state sequence confirmed this finding, better depicting a tubular morphology of the pituitary stalk in the absence of sphenoidal meningocele (Fig 1). The sella was mildly enlarged, and there was clival hypoplasia. Additional findings included a corpus callosum body and splenium partial agenesis and a small interhemispheric arachnoid cyst (Fig 1).

Finally, bilateral supraclinoid ICA and M1 MCA segment narrowing was detected on MRA, with thin collateral lenticulostriate vessels, suggestive of Moyamoya syndrome (Fig 3). Due to these findings and the history of headache, a DSC PWI study was performed, indicating a preserved cerebrovascular reserve capacity. 


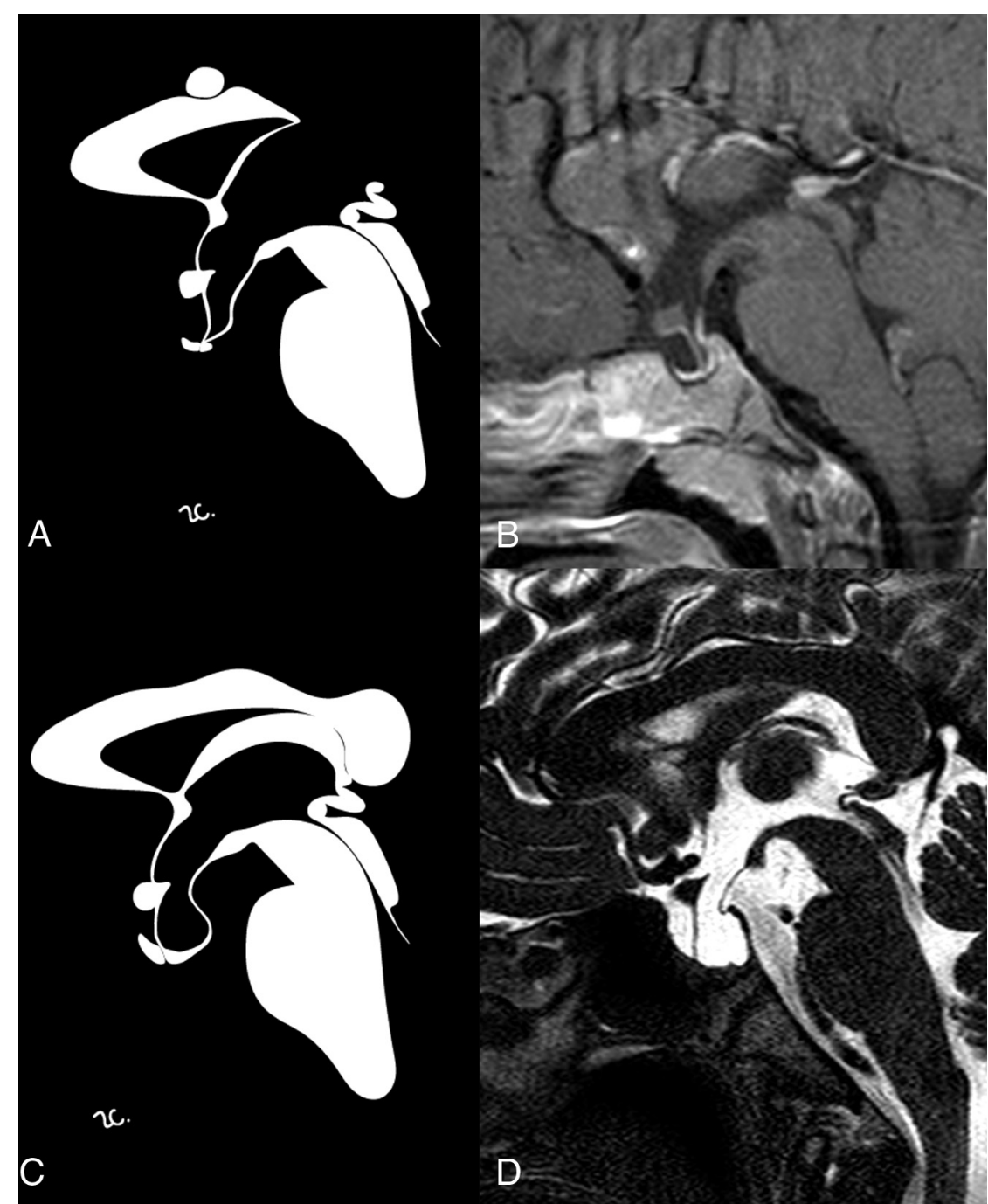

FIG 1. Sagittal contrast-enhanced T1-weighted $(B)$ and high-resolution T2-weighted $(D)$ images with corresponding stylized anatomic drawings ( $A$ and $C$ ) of patient 1 (upper row) and patient 2 (lower row) depicting the main findings reported in the text, including PEIR.

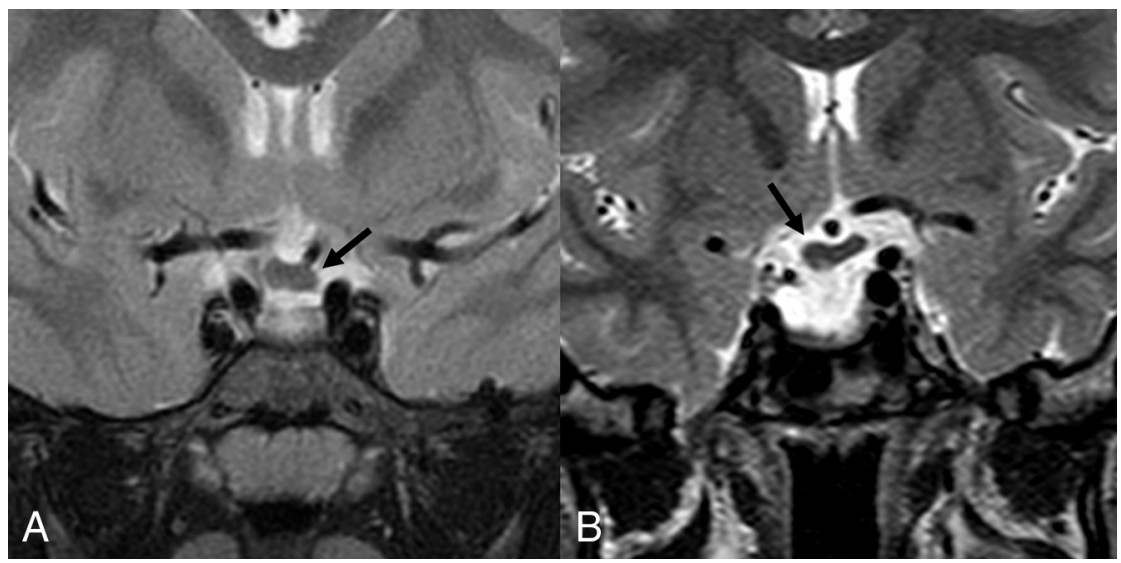

FIG 2. Coronal T2-weighted images of patient $1(A)$ and patient $2(B)$ showing thickening of the optic chiasm (arrows).

Genetic testing did not identify any PAX6 gene mutations, encoding a transcriptional regulator involved in lens placode formation, previously reported in several ocular anomalies, including MGDA. ${ }^{7}$
Patient 2. This 13-year-old boy came to our attention for short stature and chronic headache. Laboratory tests confirmed growth hormone deficiency.

Brain MR imaging showed sellar enlargement, adenohypophysis hypoplasia, and PEIR (Fig 1). The last finding was better defined on a sagittal driven equilibrium sequence, which demonstrated an evident communication between the third ventricle and sella turcica. The infundibular recess was, in fact, absent, and consequently, the pituitary stalk had a tubular appearance with thin walls.

The right part of the optic chiasm and the ipsilateral prechiasmatic optic nerve were displaced slightly downward. On the same side, partial hypoplasia of the sphenoid body with a small meningoencephalocele was found (Fig 2). A thin posterior defect of the right ocular globe was also noted. The corpus callosum was uniformly slightly thickened (according to Garel et $\mathrm{al}^{8}$ ), but not clearly dysplastic.

MRA detected right ICA hypoplasia with severe supraclinoid narrowing and distal basilar artery stenosis (Fig 3). DSC-PWI showed only mild elongation of right frontal lobe MTT. This, associated with MRA findings, prompted yearly follow-up MR imaging which, during a 3-year period, did not show progression.

On the basis of these findings, MGS was suspected, and the patient underwent an ophthalmologic evaluation, confirming an MGDA.

\section{DISCUSSION}

MGDA is a sporadic condition, but it has been previously described as an isolated finding in a mother and child. ${ }^{9}$ Our patients were initially referred for pituitary MR imaging due to growth hormone deficiency, revealing a PEIR. The pituitary stalk was apparently duplicated on coronal images because of its tubular morphology and direct communication with the third ventricle. This finding should be carefully evaluated to avoid a potential misdiagnosis of other pituitary stalk malformative conditions, such as duplication. ${ }^{2}$ The anomalous infundibulum perforation, in the absence of meningoencephaloceles, was clearly defined by high-resolution volumetric T2-weighted sequences (CISS and driven equilibrium in 


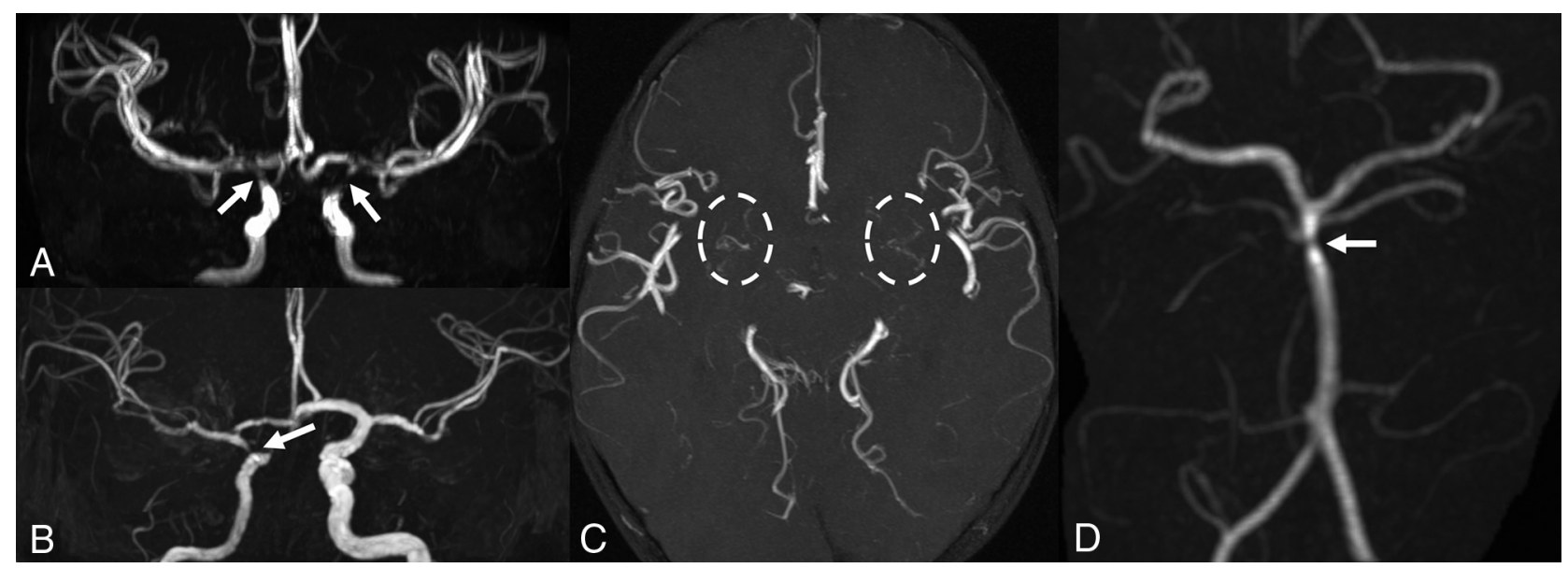

FIG 3. MR angiography. Patient 1 ( $A$ and $C$ ) has bilateral focal stenoses of the internal carotid arteries (arrows) with thin collateral vessels in the lenticulostriate regions (dashed circles). Patient 2 shows unilateral stenosis of the right internal carotid $(B)$ and basilar $(D)$ arteries (arrows).

our cases). To the best of our knowledge, among reported MGDA cases in the literature, none had associated PEIR.

Among the possible midline abnormalities reported in MGS, there is the craniopharyngeal canal, not present in our patients. ${ }^{10}$ It represents a rare, well-corticated midline channel of the sphenoid body that develops from the sellar floor to the nasopharynx. Its origin has been hypothesized from incomplete closure of the Rathke pouch, the precursor of the adenohypophysis. This entity can be variably associated with encephalocele and hypopituitarism, most likely due to ectopic adenohypophysis and even tumors (gliomas, dermoids, teratomas, craniopharyngiomas, or adenomas). ${ }^{11}$

Both of our patients had chiasmatic abnormalities with thickening and inferior drooping. On the basis of our experience and the lack of progression on follow-up imaging, we agree with Doneda et $\mathrm{al}^{12}$ on the dysplastic and not neoplastic nature of the chiasmal thickening. In our second patient, in the absence of sellar floor defects, chiasmatic prolapse was related to ipsilateral sphenoidal hypoplasia, which could be considered the less severe form of a sphenoid malformative spectrum ending with a meningoencephalocele.

While corpus callosum partial agenesis has already been described in MGS, ${ }^{2}$ global thickening, as observed in the second case, though in the absence of dysmorphisms or psychomotor delay, has never been reported.

Intracranial vascular abnormalities in MGS, not necessarily ipsilateral to the optic disc anomaly, could be due to the close relationship of the ICA and optic vesicle development during the fourth week of gestation. ${ }^{1,4,12}$ Arterial involvement, most commonly affecting the anterior circulation, ranges from mild hypoplasia to focal stenosis or complete agenesis and progressive Moyamoya syndrome. ${ }^{3,13}$ Arterial alterations in our patients were not associated with cerebrovascular reserve impairment. While it is not possible to completely exclude Moyamoya syndrome without more prolonged monitoring, we believe a nonprogressive arterial dysplasia is a more probable diagnosis. We recommend PWI in addition to MRA and follow-up for MGS-associated vasculopathy evaluation.

\section{CONCLUSIONS}

While different craniofacial, pituitary, optic, vascular, and cerebral midline anomalies have been previously reported in association with MGDA, our patients are the first in whom PEIR has also been found. Neuroradiologists should be aware of the possible presence of PEIR in patients with MGS, to aid in the differential diagnosis including other pituitary malformations such as pituitary stalk duplication. We also suggest the use of high-resolution T2-weighted sequences on the sagittal plane to better define the infundibulum in case of abnormalities.

\section{ACKNOWLEDGMENTS}

The authors thank Rosanna Cianniello for the anatomic drawings.

\section{REFERENCES}

1. Thoma D, Nijs I, Demaerel P, et al. Morning glory disc anomaly with an ipsilateral enlargement of the optic nerve pathway. Eur J Paediatr Neurol 2017;21:787-791 CrossRef Medline

2. Kalra VB, Gilbert JW, Levin F, et al. Spectrum of MRI findings in morning glory syndrome. Neurographics 2014;4:56-60 CrossRef

3. Nezzar H, Mbekeani JN, Dalens H. Morning glory syndrome with carotid and middle cerebral artery vasculopathy. Optom Vis Sci 2015;92:e437-41 CrossRef Medline

4. Ellika S, Robson CD, Heidary G, et al. Morning glory disc anomaly: characteristic MR imaging findings. AJNR Am J Neuroradiol 2013; 34:2010-14 CrossRef Medline

5. Steno A, Popp AJ, Wolfsberger $S$, et al. Persisting embryonal infundibular recess. J Neurosurg 2009;110:359-62 CrossRef Medline

6. Belotti F, Lupi I, Cosottini M, et al. Persisting embryonal infundibular recess (PEIR): two case reports and systematic literature review. J Clin Endocrinol Metab 2018;103:2424-29 CrossRef Medline

7. Azuma N, Yamaguchi Y, Handa H, et al. Mutations of the PAX6 gene detected in patients with a variety of optic-nerve malformations. Am J Hum Genet 2003;72:1565-70 CrossRef Medline

8. Garel C, Cont I, Alberti C, et al. Biometry of the corpus callosum in children: MR imaging reference data. AJNR Am J Neuroradiol 2011; 32:1436-43 CrossRef Medline

9. Nagy V, Kettesy B, Toth K, et al. Morning glory syndrome: a clinical study of two cases [in German]. Klin Monbl Augenheilkd 2002;219: 801-05 CrossRef Medline

10. Kasim N, Choudhri A, Alemzadeh R. Craniopharyngeal canal, morning glory disc anomaly and hypopituitarism: what do they 
have in common? OxfMed Case Reports 2018;2018:omy018 CrossRef Medline

11. Abele TA, Salzman KL, Harnsberger HR, et al. Craniopharyngeal canal and its spectrum of pathology. AJNR Am J Neuroradiol 2014; 35:772-77 CrossRef Medline

12. Doneda C, Pinelli L, Scaramuzzi M, et al. Morning glory disc anom- aly associated with ipsilateral optic nerve and chiasm thickening: three cases and review of the literature. Neuropediatrics 2017;48: 463-66 CrossRef Medline

13. Lenhart PD, Lambert SR, Newman NJ, et al. Intracranial vascular anomalies in patients with morning glory disk anomaly. Am J Ophthalmol 2006;142:644-50 CrossRef Medline 